\title{
PARLAMENTO Y ESTADO DE ALARMA ${ }^{1}$
}

\author{
José Tudela Aranda \\ Letrado de las Cortes de Aragón. \\ Secretario General de la Fundación "Manuel Giménez Abad"
}

Cómo citar este artículo / Citation: Tudela Aranda, J. (2021). Parlamento y estado de alarma.

Garrido López, C. (coord.)

Excepcionalidad y Derecho: el estado de alarma en España,

Colección Obras colectivas, Fundación Manuel Giménez Abad, Zaragoza.

DOI: $\underline{\text { https://doi.org/10.47919/FMGA.OC21.0006 }}$

SUMARIO: I. LAS PREMISAS: 1. Las premisas de una crisis. 2. Parlamento, excepción y control. II. LOS HECHOS (I). LA PRIMERA ALARMA POR LA COVID-19: 1. La primera alarma. 2. La desescalada y la nueva normalidad. IIII. LOS HECHOS (II). LA SEGUNDA ALARMA POR LA COVID-19. EL PARLAMENTO DORMIDO. IV. LOS PARLAMENTOS AUTONÓMICOS EN LA TERCERA FASE. V. CONCLUSIÓN. UNA OPORTUNIDAD PERDIDA

\section{LAS PREMISAS}

\section{Las premisas de una crisis}

Las páginas que siguen tienen una premisa que no puede darse por implícita. En ellas, el protagonista no es el estado de alarma. El análisis se centra en el Parlamento. En concreto, en el hacer y deber hacer de la institución ante una situación caracterizada por su excepcionalidad y por enfrentar tensiones

\footnotetext{
${ }^{1}$ Este trabajo se inserta en el desarrollo del proyecto de investigación (PID2019-104414GBC31), "El control y la responsabilidad política en el Estado constitucional con especial referencia al Parlamento en el contexto multinivel", financiado por el Ministerio de Economía y Competitividad.
} 
objetivamente singulares. Consecuentemente, no me extenderé en pormenores estrictamente relativos a los estados de excepción y, en concreto, al estado de alarma. El lector tiene en este volumen, y en otros excelentes trabajos, material para complementar en lo que sea preciso lo que aquí se expondrá ${ }^{2}$. En todo caso, realizaré alguna reflexión vinculada con este particular como puente necesario para poder transitar a la relación entre el Parlamento y el estado de alarma. Pero antes de ello, realizaré una puntualización adicional.

Comprender la dinámica de cualquier institución jurídica requiere siempre no obviar el espacio y en el tiempo en el que se desenvuelve. En este caso, el ejemplo para ilustrar esta afirmación no puede ser más sencillo y recurrente. El Congreso de los Diputados también se tuvo que enfrentar a una declaración de estado de alarma con motivo de la huelga de controladores en $2010^{3}$. Sin embargo, el presupuesto de hecho era completamente diferente. Por grave que fuese el perjuicio, sus consecuencias no admiten comparación con las de la pandemia. Entre otras cosas, por la diferencia de sujetos afectados y la intensidad y generalidad de las medidas adoptadas. La coincidencia en la necesidad de resolver este problema planteado por un colectivo reducido y las consecuencias claramente limitadas de la declaración del estado de alarma, explican circunstancias como la pacífica aceptación política de una declaración que podía suscitar dudas por la inadecuación del supuesto de hecho a la declaración de un estado excepcional, así como el plazo de su prórroga. De hecho, el plazo de un mes se fijó a petición del propio Congreso para evitar tener que reunirse en el mes de enero. El estado de alarma que origina estas páginas tiene unos presupuestos completamente diferentes. Así, se puede

\footnotetext{
${ }^{2}$ VILLALÓN CRUZ, P.: "El nuevo derecho de excepción", Revista Española de Derecho Constitucional, núm. 2, pp. 93-130; REQUEJO RODRÍGUEZ, P., "Teoría Vs práctica del estado de alarma en España" en VV.AA., Constitución y democracia: ayer y hoy. Libro homenaje a Antonio Torres del Moral, Universitas, Vol. II, pp. 1499-1514; GARRIDO LÓPEZ, C.: "Naturaleza jurídica y control jurisdiccional de las decisiones constitucionales de excepción", Revista Española de Derecho Constitucional, núm. 110, 2017, pp. 47-73. Para una visión general de los problemas constitucionales de los estados de excepción, VALADÉS, D., "Problemas constitucionales de los estados de emergencia" en BARCELÓ ROJAS, D., DÍAZ RICCI, S., GARCÍA ROJA, J., GUIMARAES TEIXERA ROCHA, M. E., Covid 19 y parlamentarismo, UNAM-Instituto Iberoamericano de Derecho Constitucional-Instituto de Derecho Parlamentario, 2020; SOLOZÁBAL ECHAVARRÍA, J. J., Algunas consideraciones constitucionales sobre el estado de alarma en BIGLINO CAMPOS, P. y DURÁN ALBA, J. (Dirs.), Los efectos horizontales de la Covid-19 sobre el sistema constitucional: estudios sobre la primera oleada, Fundación Manuel Giménez Abad, Zaragoza, 2021.

3 JIMÉNEZ VILLAREJO, J., "La militarización de los controladores", El País, 13-12-2010. Disponible en línea: http://elpais.com/diario/2010/12/13/opinion/1292194804_850215.html.
} 
decir que su primera característica es su singularidad. Se puede alegar que cualquier estado de excepción es único, que cada uno presenta singularidades que impiden una comparación automática con otro. Pero el originado por la covid-19 excede lo habitual y hace preciso extenderse un poco en ello.

Una prueba es el debate existente sobre si por las medidas adoptadas debiera haberse adoptado el estado de excepción o si, por el contrario, la situación se correspondía plena, y exclusivamente, con las propias de un estado de alarma. Incluso, hay quien sostiene que no hubiese sido necesario ni siquiera activar el estado de alarma, que la legislación administrativa hubiese sido suficiente. Al margen de esta última tendencia, con vigencia básicamente entre administrativistas, el debate sobre si alarma o excepción se ha generado alrededor de una diversa concepción de los presupuestos jurídicos y teóricos de los mismos. Por una parte, quienes consideran que lo que caracteriza y determina la declaración de un estado u otro es el presupuesto de hecho, entienden que la situación originada por la pandemia se corresponde nítidamente con el estado de alarma, al estar ausente cualquier incidencia sobre el orden público. Por el contrario, quienes entienden que son las medidas adoptadas las que deben determinar si se adopta uno u otro estado, consideran que la intensidad e importancia de las medidas adoptadas, que llegarían a la suspensión de derechos fundamentales, hubiesen obligado a la declaración del estado de excepción, haciendo inadecuada la alarma ${ }^{4}$.

Junto a lo anterior, dos cuestiones adicionales deben ser mencionadas. Las dos, como se verá, se encuentran indisolublemente vinculadas al examen del hacer del Parlamento en esta crisis. Me refiero a la incidencia de las medidas adoptadas por las distintas autoridades en relación con los derechos y libertades, en concreto al debate sobre si se trataba de suspensión o de una mera limitación de derechos. La segunda cuestión, lógicamente, se refiere a la extensión temporal del estado de alarma. En el momento en el que se escriben estas páginas, diciembre de 2020/enero de 2021, y si no sucede nada que obligue a prorrogar la alarma actual, España habrá vivido bajo estado de alarma alrededor de diez meses desde marzo de 2020 hasta mayo de 2021. Un periodo suficientemente largo como para suscitar por si mismo algunas

\footnotetext{
${ }^{4}$ Defendiendo la inadecuación del estado de alarma con las medidas adoptadas, ARAGÓN REYES, M.: Epílogo en Los efectos horizontales de la Covid-19 sobre el sistema constitucional: estudios sobre la primera oleada, ob. cit. En un sentido contrario, CRUZ VILLALÓN, P., "La Constitución bajo el estado de alarma", El País, 17 de abril de 2020. Disponible en línea: https://elpais.com/elpais/2020/04/16/opinion/1587025782_733659.html.
} 
preguntas. Preguntas que, inevitablemente, se acrecentarán cuando se observe la muy diferente actuación del Parlamento en los dos ciclos en los que se divide este tiempo de excepcionalidad.

Junto a lo anterior, cuando se examina el rol del Parlamento en la crisis originada por la covid-19, es necesario realizar una referencia de índole subjetiva. Inevitablemente, en muchas ocasiones la voz Parlamento se asocia a las Cortes Generales. $Y$ sin duda, este órgano constitucional ha tenido el mayor protagonismo y una parte relevante del análisis debe centrarse en el mismo ${ }^{5}$. Ahora bien, como es sabido, la realidad parlamentaria en España no se limita a las Cortes Generales. En España existen dieciocho Parlamentos, diecinueve Cámaras. Los diecisiete Parlamentos autonómicos han tenido también un rol relevante durante esta crisis. Inevitablemente, por la necesidad de afrontar su actividad habitual en circunstancias excepcionales. Pero, más allá, porque les ha correspondido, o les debiera haber correspondido, un particular protagonismo alrededor del segundo periodo de alarma por haber delegado el Gobierno de la Nación en los Presidentes de las Comunidades Autónomas la adopción de decisiones en torno a la pandemia. Por ello, dedicaré un espacio singular a su hacer (o no hacer). En todo caso, desde estas líneas iniciales debe quedar claro que el juicio que se realice de la actividad parlamentaria durante estos meses, debería ser un juicio global. Es preciso generalizar en España una visión global del trabajo del Parlamento y esta crisis ha resultado expresiva sobre este punto.

\section{Parlamento, excepción y control.}

Desde las premisas anteriores y como puente para el análisis concreto de lo sucedido, es preciso recordar siquiera sea de forma sucinta algunos presupuestos sobre la relación entre las situaciones de excepción y la actuación del Parlamento. Me limitaré a expresar aquellas ideas que estimo esenciales para enmarcar adecuadamente las reflexiones que se realizaran en las páginas siguientes.

En primer lugar, hay que recordar lo que nuestro ordenamiento jurídico establece sobre este extremo. El artículo 116 de la Constitución dedica su

\footnotetext{
${ }^{5}$ GARCÍA ESCUDERO, P., "Actividad y funcionamiento de las Cortes Generales durante el estado de alarma por Covid-19" en TUDELA ARANDA, J. (Coord.), El Parlamento ante la Covid-19, Fundación Manuel Giménez Abad, Cuadernos Monografías núm. 8, 2020, pp. 18-27.
} 
párrafo segundo al estado de alarma, señalando que el Gobierno podrá decretarlo por un plazo máximo de quince días, dando cuenta inmediata al Congreso, sin cuya autorización no lo podrá prorrogar ${ }^{6}$. La intervención del Congreso incrementará su intensidad en los estados de excepción y sitio. En el supuesto del estado de excepción, el Congreso deberá autorizar previamente la declaración. Y en el estado de sitio, su protagonismo será absoluto, ya que le corresponderá determinar el ámbito territorial, duración y condiciones ${ }^{7}$. Sin duda, estas diferencias se relacionan con la gravedad de las medidas que pueden ser adoptadas en cada uno de los supuestos. Y ello no es ocioso para el estudio del supuesto particular que se examina, ya que, precisamente, una de sus características ha sido la objetiva intensidad de las decisiones adoptadas en relación con los derechos y libertades, con independencia del debate sobre si se ha llegado o no a suspender derechos. En todo caso, podría pensarse que de esa intensidad se debe deducir un criterio interpretativo en relación con la necesaria intervención del Congreso.

Para completar este somero análisis constitucional, es preciso referirse al párrafo $5^{\circ}$ que bien puede considerarse como una cláusula de garantía del poder legislativo frente a la acción del ejecutivo en cualquiera de los estados de excepción. Al respecto, es preciso destacar que en el mismo se establecen dos significativas premisas. Por la primera, se impide al Gobierno disolver el Congreso estando vigentes cualesquiera de estos estados. Por la segunda, se impone la necesidad de actividad. Declarado cualquiera de ellos, las Cámaras quedarán inmediatamente convocadas si estuvieran fuera del periodo de sesiones y su funcionamiento no podrá ser interrumpido. En el caso de que el Congreso estuviese disuelto, se hace previsión expresa de que sus competencias serán ejercidas por la Diputación Permanente.

La Ley Orgánica 4/1981, de 1 de junio de los Estados de alarma, excepción y sitio, no aporta grandes novedades. En el Capítulo I, referido a las disposiciones comunes a los tres estados, sólo es posible encontrar dos disposiciones que sean de interés para el tema objeto de estudio. La primera es reiteración de la determinación constitucional de que la declaración de cualquiera de los estados excepcionales no podrá interrumpir el normal

\footnotetext{
${ }^{6}$ Sobre el artículo 116 de la Constitución, TORRES MURO, I., "Comentario al artículo 116 de la Constitución" en CASAS BAAMONDE, M. E. y RODRÍGUEZ-PIÑERO BRAVO-FERRER, M., Comentarios a la Constitución española, Segunda edición, Fundación Wolters Kluver, 2018, Volumen II, pp. 630-638.

${ }^{7}$ CRUZ VILLALÓN, P., El Estado de sitio y la Constitución, Centro de Estudios Políticos y Constitucionales, 1980.
} 
funcionamiento de los poderes del Estado. La segunda es más relevante a nuestros efectos. El párrafo $2^{\circ}$ del artículo 1 señala expresamente que las medidas a adoptar y la duración de los mismos serán, en cualquier caso, las estrictamente indispensables para asegurar el restablecimiento de la normalidad y su aplicación deberá realizarse de forma proporcionada a las circunstancias ${ }^{8}$.

El Capítulo II de la Ley se dedica al estado de alarma. En el tema que se estudia, poco añade a lo señalado por la Constitución. Literalmente, el artículo 6.2 establece que sólo se podrá prorrogar con autorización expresa del Congreso de los Diputados que podrá establecer el alcance y las condiciones vigentes durante la prórroga. De su posible plazo, nada se dice. Por otra parte, en el artículo 8.1 se señala que el Gobierno facilitará al Congreso cuánta información le solicite y que también dará cuenta de los decretos que dicte durante la vigencia del estado de alarma. Como es sabido, el argumento más relevante utilizado para defender que no hay limite temporal para la prórroga del estado de alarma, es que, como se ha visto, ni la Constitución ni la Ley lo establecen. Por el contrario, la Ley sí fija el límite expreso de treinta días para la declaración del estado de excepción (artículo 15.3). Finalmente, el Reglamento del Congreso de los Diputados regula en su artículo 162 el procedimiento de autorización de la declaración del estado de alarma ${ }^{9}$. Lo hace de forma sucinta, limitándose de hecho a reproducir el presupuesto constitucional con algún añadido procedimental escasamente relevante. Los poderes del Congreso en esta materia no se ven ampliados por su Reglamento, algo que bien podría haber sucedido.

La referencia al marco normativo debe cerrarse con alguna reflexión extraída de la STC 83/2016, de 28 de abril que resolvió el recurso de amparo interpuesto con motivo de la anterior, y hasta el momento única, declaración del estado de alarma con motivo de la huelga de controladores. La Sentencia no afecta directamente al tema que se estudia, ya que se centra en la determinación del rango normativo de la declaración del estado de alarma. Pero contiene alguna reflexión de interés para la necesaria labor interpretativa.

\footnotetext{
${ }^{8}$ Al respecto, VELASCO CABALLERO, F.: Estado de alarma y distribución territorial del poder, El Cronista del Estado Social y Democrático de Derecho, núms. 86-87, Coronavirus y otros problemas, pp. 84-85.

${ }^{5}$ Vid GALINDO ELOLA-OLASO, F., GONZÁLEZ ESCUDERO, A., LÓPEZ MOREO DE CALA, M. y SIEIRA MUCIENTES, S., "Comentarios a los artículos 162-165 del Reglamento del Congreso" en RIPOLLÉS SERRANO, M. R. (Coord.), Comentarios al Reglamento del Congreso de los Diputados, Congreso de los Diputados, 2012, pp. 1124-1146.
} 
Por una parte, el Tribunal declara que la intervención del Congreso no es sólo control político sino una auténtica autorización que determinará el alcance y condiciones de la alarma si se decide su prórroga (FJ $7^{\circ}$ ). Por otra, señala expresamente que el Decreto y sus prórrogas se insertan en el sistema de fuentes del derecho de excepción. Una legalidad excepcional que durante la vigencia del estado de alarma "desplaza la legislación ordinaria", en la medida que afecta, modifica o modula durante ese periodo la aplicabilidad de leyes o normas con rango de ley, de lo que deduce el valor normativo equiparable a las leyes de esa declaración y sus prórrogas (FJ 10).

$\mathrm{Ni}$ el marco normativo ni la Sentencia del Tribunal Constitucional son demasiado expresivas sobre la intervención del Congreso de los Diputados en relación con el estado de alarma, más allá de establecer el requisito mínimo e indispensable de la autorización en caso de solicitud de prórroga. Con todo, se pueden extraer algunas directrices de utilidad para una interpretación general. Así, del artículo 116 se puede deducir que la intervención del Congreso en relación con las situaciones de excepción tiene, básicamente, una función de garantía. Una garantía frente al poder que debe entenderse como suplementaria de la que tradicionalmente le corresponde a un Parlamento frente al ejecutivo. Situaciones excepcionales pueden requerir poderes excepcionales pero también controles añadidos. En este punto, creo que se debe hacerse notar una circunstancia no jurídica, meramente política, que es presupuesto del diseño jurídico y que por su inexistencia durante esta crisis puede explicar algunas cosas. Me refiero a que el presupuesto de todas las dinámicas político constitucionales en la forma de gobierno parlamentaria es la existencia de una mayoría de gobierno estable que garantiza las decisiones del ejecutivo. En España, al menos hasta el momento, esa mayoría no existe. El Gobierno la alcanza gracias a acuerdos con fuerzas nacionalistas minoritarias que imponen un alto precio a su voto. En mi opinión, ello explica, al menos parcialmente, que desde el ejecutivo se haya buscado una interpretación restrictiva de la posible actividad del Parlamento en la crisis y, por tanto, de la idea de garantía que subyace a cualquier situación excepcional.

Desde la idea general de garantía que se anuda a todos lo estados de excepción, hay otro dato que no debe dejar de mencionarse. Como se indicó, el artículo 116 gradúa la intensidad de la intervención del Congreso en función del estado que se declare. Obviamente, ello se corresponde con las medidas que pueden adoptarse en cada uno de ellos y, en particular, con las afecciones 
a los derechos fundamentales que conllevan. Dado que en esta ocasión el estado de alarma se ha acompañado de una incidencia sobre los derechos fundamentales y libertades aún más intensa de lo que en principio se correspondería con un estado de alarma "ordinario", cabe deducir que debería haberse realizado una interpretación amplia de las garantías que correspondería ejercer al Congreso. Una intervención que creo es independiente de si se entiende que hubo o no suspensión de derechos. Lo relevante es que en cualquier caso la intensidad de las afecciones fue profunda y generalizada tanto por el número de derechos y libertades afectados como por su extensión geográfica y temporal. Esta interpretación se vería fortalecida por los criterios que impone la Ley Orgánica 4/1981 sobre la adopción y aplicación de medidas. Deben ser las estrictamente indispensables y aplicadas de forma proporcionada (artículo 1.2). Parece evidente que es al Parlamento a quien le corresponde en primera instancia garantizar estos requisitos. En una situación como la provocada por la pandemia, que ha exigido la generalización geográfica de las medidas; una larga extensión temporal; y, como se dijo, de medidas con incidencia notable en los derechos, cercanas a la suspensión en algún caso, parece lógico concluir que el Parlamento debiera haber encontrado una fórmula para ejercer en plenitud su función de garantía. Se puede sintetizar diciendo que una situación excepcional e, incluso, singular respecto de los supuestos tradicionales del estado de alarma hubiese requerido un régimen "singular" de respuesta parlamentaria. Esta idea se refuerza por el contenido del párrafo 5ํํㄹ del artículo 116 de la Constitución, del que, como se vio, puede deducirse una auténtica cláusula de garantía parlamentaria en relación con los estados de excepción.

Finalmente, de la STC 83/2016, cabe rescatar la idea de que la declaración del estado de alarma supone la emergencia de un derecho de excepción que durante su vigencia desplaza la legalidad ordinaria. La relevancia y consecuencias de esta afirmación son obvias. Su incidencia sobre la función legislativa del Parlamento también, aunque no estén del todo claras. Con todo, es evidente que el reconocimiento de que la declaración del estado de alarma conlleva la emergencia de un orden excepcional obliga a insistir en la necesidad de una interpretación restrictiva del mismo y expansiva de las facultades de garantía del Parlamento.

Una conclusión perfectamente coherente con las premisas de las que necesariamente debe partir el análisis de cualquier situación de excepción que 
conlleve concentración del poder. El Estado constitucional se define por el control del poder. El Parlamento tiene en el control la primera de sus funciones, aquella que le define por esencia en el conjunto del sistema institucional ${ }^{10}$. La propia previsión de los estados de excepción responde a esta idea. Son garantía del orden constitucional porque el poder excepcional que necesariamente conllevan para resolver una situación extraordinaria, se somete a derecho y, en particular, a los presupuestos del Estado constitucional, básicamente, el control del poder. Un control que se refuerza para poder responder con eficacia a los retos derivados de la emergencia. Porque, hay que recordarlo, anticipando algo que se señalará posteriormente, los controles que se establezcan de forma específica en relación con el estado de alarma no sustituyen a los controles ordinarios. Los refuerzan, son suma, no resta.

Finalmente, subrayaría que por definición y por las propias características de los presupuestos del estado de alarma, se trata de una situación transitoria con una extensión acotada en el tiempo. Si no hay novedad, España habrá vivido casi un año estrictamente bajo estado de alarma y más de un año con medidas excepcionales. Creo que debería haberse reparado en ello. Nadie niega la necesidad de la extensión del plazo. Pero no es posible obviar la relevancia que conlleva. Por ello, parece plausible plantear que para limitar los efectos del derecho de excepción, hubiese sido deseable buscar alternativas jurídicas menos traumáticas.

\section{LOS HECHOS (I). LA PRIMERA ALARMA POR LA COVID-19}

\section{La primera alarma.}

A pesar de que cuando se escriben estas líneas, la epidemia se encuentra lejos de finalizar y que aún se encuentra vigente la segunda declaración de estado de alarma, los trabajos sobre las consecuencias jurídicas de la misma y sobre los problemas asociados, se han multiplicado hasta el extremo de que se puede afirmar de que a estas alturas se dispone de un importante bagaje

\footnotetext{
${ }^{10}$ ARAGÓN REYES, M., El control parlamentario como control político, en Revista de Derecho Político, núm. 23.
} 
doctrinal ${ }^{11}$. Precisamente, una de las cuestiones más y mejor estudiada ha sido el rol del Parlamento en relación con la declaración del primer estado de alarma $^{12}$. Por ello, no me detendré demasiado en este punto, más allá de recordar sucintamente lo sucedido y extraer de ello alguna consecuencia relevante para el conjunto del análisis. Reflexión adicional y singular merece la segunda etapa de la pandemia, asociada a lo que vino en denominarse desescalada y nueva normalidad. Alrededor de la misma se ha reflexionado menos sobre su relación con la actividad del Parlamento. La razón evidente es que, en teoría, se trataba de una etapa de "normalidad" y que, por ende, al Parlamento sólo le correspondía actuar con normalidad. Un presupuesto que creo erróneo y en el que me extenderé posteriormente por conectar bien con la línea argumental que se defiende en estas páginas.

El 14 de marzo de 2020, el Presidente del Gobierno anunció que se procedía a declarar el Estado de alarma (Real Decreto 463/2020). La razón, la extensión extraordinaria por su intensidad, y generalizada a todo el territorio nacional, de un virus presuntamente llegado desde China y que en escaso tiempo se había convertido en pandemia. En el momento de declaración, la situación sanitaria era ya grave. Por otra parte, no había posibilidad de establecer una previsión medianamente fiable. Las epidemias parecían que pertenecían al pasado, habían desaparecido de nuestro imaginario, y, además, se trataba de un agente infeccioso totalmente desconocido. Desde el primer momento, se era consciente de que el plazo inicial de quince días, debería prorrogarse. En este caso, no había duda de que se trataba de uno de los presupuestos arquetípicos del estado de alarma (artículo 4.b de la LO 4/1981). Las medidas adoptadas fueron especialmente graves. Hasta el extremo, como es conocido, que un sector doctrinal entiende que debiera haberse declarado el estado de excepción, que la alarma no daba amparo a las mismas. Sin entrar en la polémica, se puede observar que se trata de un presupuesto típico del estado de alarma con medidas, sea cual sea su estricta calificación, cercanas a las que caracterizan el estado de excepción. Una dicotomía que, creo, más allá de

\footnotetext{
${ }^{11}$ Entre otros trabajos, véase el citado número monográfico dedicado por El Cronista, ya en abril de 2020 y las obras colectivas Covid 19 y parlamentarismo, ob. cit. y Los efectos horizontales de la Covid-19 sobre el sistema constitucional: estudios sobre la primera oleada, opinión pública, ob. cit.

12. Al respecto, El Parlamento ante la Covid-19, ob. cit. Y los trabajos de GARCíA ROCA, J., GENTILE, J. H. y ROSSET, P., en Covid 19 y parlamentarismo, ob. cit.
} 
discusiones teóricas, debería haber tenido en cuenta el Parlamento para determinar el alcance de su intervención ${ }^{13}$.

Sin embargo, el Parlamento aún tenía una exigencia más perentoria. Su rol en relación con la declaración del estado de alarma estaba establecido en las normas. Como salvar una situación como la provocada por la pandemia, no ${ }^{14}$. Ya con anterioridad a la declaración del estado de alarma, algunos diputados se habían contagiado de covid-19. De esta manera, el primer desafío que la epidemia planteaba a los dieciocho Parlamentos españoles era puramente logístico. La agresividad de la epidemia impedía, incluso con la adopción de las correspondientes medidas de seguridad, el funcionamiento normal de la actividad parlamentaria. Ningún Parlamento tenía un plan de contingencia frente a esta situación y en la mayoría de los casos, los medios para poder hacerla frente eran escasos sino inexistentes. Esta lógica confusión tuvo un inevitable impacto en las primeras semanas. Un tiempo que, hay que recordar, fue de desconcierto absoluto y miedo, sin que ninguna de estas palabras sobre. Ahora bien, la premisa del Parlamento debía ser inequívoca. Su presencia y activismo era más necesario que nunca. $Y$ no sólo por la necesidad de controlar un poder extraordinario. También porque era absolutamente preciso que los ciudadanos tuviesen en sus representantes el liderazgo que el momento exigía.

Pero los problemas a los que debían enfrentarse los Parlamentos no eran sólo de carácter logístico, debidos a las carencias de los medios precisos para hacer frente a una situación similar. También eran problemas jurídicos, básicamente vinculados a un requisito tradicional del trabajo parlamentario, la presencialidad, con instituciones anexas como la exigencia de quorum o la indelegabilidad del voto ${ }^{15}$. Así, reestablecer un mínimo de normalidad se enfrentó a un conjunto diverso y complejo de dificultades. Con todo, no creo que ello justifique suficientemente el que el Congreso estuviese un mes con

\footnotetext{
${ }^{13}$ Con independencia de los argumentos existentes para inclinarse en uno u otro sentido, creo que es objetivo que, si bien el presupuesto de hecho coincide con lo previsto para el estado de alarma, las consecuencias que se han anudado al mismo son más propias del estado de excepción, por la intensidad de la afección sobre los derechos y libertades. Desde esta premisa, lo que a mi juicio es insoslayable es entender que la intervención del Parlamento debe ser, en cualquier caso, de la máxima intensidad posible.

${ }^{14}$ GARCÍA ESCUDERO, P., "Actividad y funcionamiento de las Cortes Generales durante el estado de alarma por Covid-19", ob. cit., pp. 18-20.

${ }^{15}$ GARCÍA ESCUDERO, P., "Actividad y funcionamiento de las Cortes Generales durante el estado de alarma por Covid-19", ob. cit., pp. 19.
} 
actividad de mínimos, situación similar a la de muchos Parlamentos autonómicos. Incluso, algunos de ellos llegaron, literalmente a "cerrar".

Como señalé, la problemática jurídica relacionada con esta etapa ha sido ya muy bien estudiada. $Y$ aunque sin duda seguirá habiendo cuestiones controvertidas, resulta más interesante realizar algunas reflexiones de carácter genérico. Es obvio que la situación cogió completamente desprevenidos a los Parlamentos españoles. Ello era inevitable. Nadie había imaginado una situación similar. En consecuencia, era natural que hubiese un tiempo de desconcierto. Lo que resulta menos normal es que en el momento de tomar conciencia de la situación y advertidos de la intensidad de las medidas adheridas a la declaración del estado de alarma, no se activase el presupuesto institucional correspondiente. En una situación de emergencia, el Parlamento debía responder con más intensidad que nunca. Debía hacerlo como institución de contrapeso y colaboración del ejecutivo en un momento excepcional, pero también como foro de debate y liderazgo de cara a la opinión pública. No fue así. Como se indicó, durante un mes, las Cortes Generales estuvieron prácticamente paralizadas y una situación similar se vivió en la mayoría de los Parlamentos autonómicos. Para explicarlo, se alegó, y se alega, el confinamiento obligado de la población y las consiguientes dificultades para el desarrollo mínimamente normal de la institución. Esas dificultades existían, pero la actividad parlamentaria era tan indispensable como otras que, a pesar de las necesarias medidas sanitarias, se continuaron desarrollando. Incluso cuando se reanudó una cierta actividad, esencialmente telemática o con presencia muy reducida de diputados, el Parlamento, la gran mayoría de los Parlamentos, optaron por un perfil bajo. En muchas ocasiones, como en el caso del Congreso, parecía que ello era coherente con la voluntad del Gobierno. Es comprensible que en esta situación se ofreciese un perfil colaborador. Colaboración que se debería traducir en impulso y liderazgo en relación con la ciudadanía, pero también en control. En su labor de contrapeso, el Parlamento debía ayudar al ejecutivo rectificando errores (inevitables) y posibles excesos. En líneas generales, no sucedió así. Una vez más, los ejecutivos vieron en la Institución parlamentaria un obstáculo que convenía reducir al mínimo.

Si en relación con las Cortes Generales el quehacer parlamentario se salvó, fue debido a la necesaria autorización de la prórroga cada quince días. Siete prórrogas, siete debates relevantes. Como se sabe, la autorización de la 
prórroga es también oportunidad para que los grupos puedan modular la propuesta del Gobierno. Así, la importancia de este trámite es evidente. En si mismo, condensa lo que singulariza al Parlamento: debate, publicidad, pluralismo. Por todo ello, el Tribunal Constitucional pudo entender que esa autorización tenía rango de ley. En este caso, hay que subrayar la importancia del debate como tal. Durante los mismos, los ciudadanos españoles tuvimos la oportunidad de escuchar los argumentos del Gobierno sobre la necesidad de prorrogar la epidemia y los de la oposición, criticando o matizando su actuación. Entiendo que, en líneas generales, los actores no estuvieron a la altura de las circunstancias. No se trataba de un momento cualquiera y se comportaron casi como si lo fuera, persiguiendo más réditos políticos inmediatos que transmitir a la población la confianza suficiente. Desde el análisis institucional, resulta particularmente criticable el que se aprovechase la autorización de las prórrogas para introducir demandas ajenas a la situación de emergencia. La prórroga de la alarma, su autorización o no, sólo se debería condicionar a medidas directamente relacionadas con su alcance.

La visión generalista de lo sucedido en el Congreso, lógicamente escenario principal del debate, debe complementarse con una referencia a lo sucedido en el Senado y en los Parlamentos autonómicos. Comenzaré por estos últimos, ya que el juicio sobre el Senado se encuentra, pienso, relacionado con lo sucedido en las Comunidades Autónomas.

Desde un punto de vista territorial, la primera declaración del estado de alarma, se caracterizó por la centralidad de mando. Una de las consecuencias fundamentales de la aprobación del Decreto fue que la decisión quedaba concentrada en el Gobierno del Estado. Si bien formalmente no se trataba de una alteración del reparto competencial, de hecho lo era ${ }^{16}$. Las competencias en materia sanitaria eran básicamente autonómicas. Como se ha recordado, también el Estado disponía de importantes competencias en esta materia. Pero lo cierto es que las había abandonado, hasta hacer del Ministerio de Sanidad un fantasma perdido. De forma súbita, ese fantasma debía hacer frente a una grave crisis sanitaria. La concentración de mando se ejerció con rigor y si bien se reunió con frecuencia a la Conferencia de Presidentes, su objeto fue más

${ }^{16}$ VELASCO CABALLERO, F., "Estado de alarma y distribución territorial del poder", El Cronista del Estado Social y Democrático de Derecho, núms. 86-87, p. 15; DE LA QUADRASALCEDO JANINI, T., "Estado autonómico y lucha contra la pandemia". en Los efectos horizontales de la Covid-19 sobre el sistema constitucional: estudios sobre la primera oleada, ob. cit. 
informativo que decisorio. Así, en relación con el control estricto de las medidas adoptadas en relación con la pandemia, el rol de estas Cámaras era menos relevante. Pero ello no quiere decir que globalmente no lo fuese. Pronto se observó que las consecuencias de la crisis transcendían el ámbito estrictamente sanitario. El impacto social y económico era muy importante y la acción de los poderes públicos se antojaba indispensable. Junto a ello, naturalmente, había que demandar de los Parlamentos autonómicos que ejerciesen esa labor de liderazgo social antes reclamada para el Congreso. De liderazgo, publificación y racionalización del debate. La respuesta fue irregular. En algunas Comunidades, el Parlamento intentó con cierta celeridad recobrar una actividad ordinaria, si bien, lógicamente, con las limitaciones derivadas de las cautelas sanitarias y en otras, se mantuvo un perfil bajo. También merece un análisis singular las distintas respuestas jurídicas que se habilitaron para solventar los problemas originados por esas limitaciones. Me remito a los trabajos existentes sobre este extremo ${ }^{17}$.

$\mathrm{Si}$ a nivel gubernamental se puede aludir a las distintas reuniones de la Conferencia de Presidentes, nada se puede decir de una colaboración interparlamentaria $^{18}$. Es un tema al que me he referido en diversas ocasiones. La primera manifestación de la misma debería haber sido, lógicamente, entre el Senado y los Parlamentos autonómicos. Se trataba de una oportunidad excelente para reflejar la potencia de este posible marco de trabajo conjunto. El Senado podría haber sido un foro adicional no sólo para la comunicación entre las distintas Comunidades Autónomas y el Estado, sino también un lugar adecuado para que estas expresasen su parecer sobre las medidas a adoptar. Es cierto que el diseño normativo del Senado no es el más adecuado para que puede desempeñar sus funciones como Cámara territorial. Pero también lo es que, con imaginación y voluntad, podría desempeñar un papel relevante en las relaciones territoriales. Asimismo, hubiese sido posible plantear algunos ámbitos de colaboración e intercambio de información entre Parlamentos de Comunidades Autónomas limítrofes, que tenían que abordar problemas comunes. Siquiera de una forma virtual, parlamentarios de una y otra

\footnotetext{
${ }_{17}^{17}$ Véase, EL Parlamento ante la Covid-19, ob. cit; DUEÑAS CASTRILLO, A., "Las relaciones Parlamento-Gobierno durante el estado de alarma por la Covid-19", en Los efectos horizontales de la Covid-19 sobre el sistema constitucional: estudios sobre la primera oleada, ob. cit

18 TUDELA ARANDA, J., Parlamento y crisis sanitaria. Reflexiones preliminares en El Parlamento ante la Covid-19, ob. cit., pp. 6-17.
} 
Comunidad podrían haber ofrecido a los ciudadanos una interesante imagen de unidad de acción.

Una penúltima reflexión debe tener por objeto los presupuestos materiales de la acción parlamentaria. Como se ha dicho, la primera reacción fue casi de parálisis. Si no era posible reunirse físicamente, no había Parlamento. Desde luego, la imposibilidad de reunión física debía ser matizada. Sí era posible e imprescindible una mínima presencialidad. La relevancia del quehacer parlamentario lo exigía. Con todo, y más allá de las cuestiones jurídicas que pudieran plantearse, existía una objetiva dificultad material para poder desarrollar el trabajo en plenitud. Hasta el momento, sólo de forma excepcional se había previsto para algunos casos la posibilidad del voto telemático. La celebración de reuniones no presenciales era algo que no sólo escapaba al Reglamento. Escapaba a la imaginación. Era, simplemente, impensable. Pero súbitamente se hizo necesario tener ese tipo de reuniones. Una necesidad que puso de manifiesto tanto la precariedad de los medios presentes como la necesidad de disponer para el futuro de una logística potente que permita hacer frente a este tipo de situaciones.

Lograr la autorización del Congreso fue haciéndose progresivamente más complejo. La acumulación de solicitudes, la disminución de la intensidad de la pandemia y el oportunismo político, se sumaron para que los partidos políticos se separasen del primer apoyo incondicional a posturas diversas según los casos. Ello provocó que el debate de las últimas autorizaciones fuese especialmente tenso, llegando el Gobierno a temer que no se aprobase. Una circunstancia que alumbra sobre un hecho esencial que tendrá muy importantes consecuencias sobre la segunda alarma. El hecho de que el Gobierno no disponga de mayoría parlamentaria estable y que para lograrla tenga que realizar largas y difíciles negociaciones será determinante de que en ese segundo periodo se opte, simplemente, por evitar solicitarla. Así, la cuestión no es tanto si el plazo de la prórroga es demasiado corto o no como la precariedad parlamentaria sobre la que se sostiene el Gobierno.

En todo caso, como balance general de esta primera etapa, se puede se puede hablar de un Parlamento diluido, tanto en el Estado como en las Comunidades Autónomas. No se logró transmitir la esencialidad de la institución y la consiguiente necesidad de garantizar su funcionamiento sin limitaciones. Tan sólo por lo imperiosamente necesario, la autorización de las prórrogas se garantizó esa necesidad. Sin necesidad de ese debate, en las Comunidades 
Autónomas, el perfil fue bajo. En general, no se supo encontrar la vía para, simultáneamente, transmitir control y apoyo al gobierno. Junto a ello, se podría aludir al ya mencionado déficit de medios que puso en entredicho el soporte logístico de la Institución. En todo caso, aunque los males ajenos no sean el mejor consuelo, se puede señalar que esta cierta incapacidad para responder a las circunstancias se pudo observar también en Parlamentos tan significativos como el británico ${ }^{19}$.

Finalmente, no puedo sino realizar un apunte valorativo sobre la función de control y el consiguiente rol de la oposición durante una circunstancia como la vivida. Se ha podido escuchar con bastante frecuencia que en una situación de excepción a la oposición sólo le cabía apoyar al Gobierno. Lo único importante era la salud pública y era al Gobierno a quién le correspondía determinar cómo protegerla. Creo que es un planteamiento equivocado. Por supuesto, si siempre es predicable de los actores políticos un comportamiento riguroso y que tenga presente el interés general, con mayor intensidad hay que demandarlo cuando se vive una crisis tan extraordinaria. Una exigencia extensible a todos. A gobierno y a oposición. Pero traducir ello en una política de mero asentimiento por los partidos no gubernamentales, no parece razonable. En primer lugar, se podría alegar que en España los roles de gobierno y oposición se encuentran repartidos y que en virtud de ese orden territorial las decisiones de aquí afectan allí y, en consecuencia, el silencio no es posible. Pero, más allá, asumir semejante tesis es obviar el papel de control que corresponde a la oposición. Controlar como ejercicio de limitación del poder y como oportunidad para enriquecer la acción gubernativa es esencial a la democracia siempre. $Y$ en una situación de concentración de poder, aún más. El control, la crítica rigurosa, no puede verse como un obstáculo indeseable sino como una cualidad del sistema. Quién alega que el problema es que la crítica no es ni rigurosa ni constructiva, puede llegar a tener razón en la descripción. Pero ello nunca es argumento suficiente para eliminarla. Quienes sostienen estas tesis ignoran una vertiente fundamental del ejercicio de la función parlamentaria de control. Mediante la misma, la oposición critica al Gobierno. Pero, a su vez, se somete al escrutinio de la opinión pública. Si objetivamente se ha realizado una critica inconveniente, destructiva, los

${ }^{19}$ Especialmente significativo resulta el caso británico, GUERRERO VÁZQUEZ, P., "El sistema parlamentario británico ante la Covid-19", en El Parlamento ante la Covid-19, ob. cit., pp. 200215. 
ciudadanos actuarán en consecuencia, sancionado semejante conducta. Lo esencial es que puedan formarse opinión tanto sobre lo que realmente sucede como sobre cuál es el parecer de sus representantes al respecto.

\section{La desescalada y la nueva normalidad.}

Es natural que cuando se piensa en la relación entre el Parlamento y la situación originada por la covid-19, el foco se dirija de forma espontánea a lo sucedido en relación con la declaración del estado de alarma. Y así, en consecuencia, que la mirada se concentre casi de forma exclusiva en el Congreso de los Diputados. Nadie puede discutir la relevancia, incluso la primacía de esta cuestión. Pero creo que es una visión parcial e, incluso, distorsionadora. Tener una imagen global de la institución durante estos meses, exige ir más allá. Por supuesto, es preciso tener presente qué sucedió en el interregno entre los dos estados de alarmas y conocer el rol desempeñado por el Parlamento en ese momento en relación directa con la evolución de la enfermedad. Pero, más allá, hay que enjuiciar materialmente su actividad. La cuestión no es sólo determinar la corrección jurídica del comportamiento de los distintos sujetos. Ello debería darse por supuesto. El juicio sobre el Parlamento inevitablemente suscita otra dimensión. Habrá que interrogarse sobre la adecuación de su trabajo a unas circunstancias extraordinarias con efectos transversales. En última instancia, habrá que intentar responder a la pregunta de si se ha hecho lo suficiente como para que los ciudadanos se hayan sentido representados (y protegidos) por la acción de sus representantes.

El 21 de junio, más de tres meses después de declarado, y mediando hasta seis prórrogas con las correspondientes autorizaciones del Congreso, se levantó el estado de alarma para iniciarse lo que a la postre no ha sido sino una etapa transitoria de este tiempo excepcional. La casualidad quiso que finalizase el estado de alarma el día que se iniciaba el verano. En este caso, el dato es relevante. Por dos razones. La llegada del calor impulsaba el ambiente de optimismo y relajación lógico después de la angustiosa primavera y, por otro lado, se iniciaba la temporada turística, factor importante para el devenir de la economía nacional. Si a ello se suma un excesivo optimismo del Gobierno que consideró preciso transmitir a la sociedad "la victoria frente al virus", se podrá tener una descripción esencial del estado de ánimo de la sociedad en ese 
momento ${ }^{20}$. Lo más grave había pasado y aunque pudiera ser que a finales del otoño o principios del invierno, el virus retornase, el verano había llegado para darnos una tregua.

Lógicamente, la alarma se levantó como consecuencia de una mejora sustancial de los datos sanitarios. Así, los Parlamentos que poco a poco habían incrementado su actividad, simultaneando en la mayoría de los casos la actividad virtual y la presencial, se veían abocados a una situación de normalidad. Por supuesto, debían mantenerse importantes medidas de seguridad. Pero ya nada impedía recobrar la actividad cotidiana. Una normalidad que, parecía razonable, debería estar marcada por lo sucedido. Realizar un balance; diagnosticar aciertos y errores; exigir, en su caso, responsabilidades; y estudiar un plan de futuro, tanto en relación con la posible evolución de la pandemia como sobre sus consecuencias económicas, parecían, entre otras, tareas que los Parlamentos debían acometer en esos días. Así, la intensidad de su trabajo y su presencia social, parecía abocada a incrementarse sustancialmente. Junto a ello, los gobiernos y el conjunto de las formaciones políticas tenían que vigilar la evolución de la pandemia, tratando de evitar posibles recaídas.

Este era, pienso, un marco teórico bastante ajustado a una dimensión realista del deber ser. ¿Qué sucedió? Generalizar casi nunca es una buena idea. Y en este caso es objetivamente inoportuno. Habría que estudiar caso por caso y ello desborda las posibilidades de este trabajo. Por ello, me limitaré a realizar alguna reflexión singular sobre el Congreso y otra de orden más general (e intuitiva) sobre el resto de los Parlamentos. El Congreso recuperó actividad presencial y continuo la tramitación de los asuntos pendientes. En relación con lo sucedido, concentró su actividad en la denominada Comisión para la Reconstrucción Social y Económica, que se constituyó el 7 de mayo y finalizó sus trabajos el 3 de julio de 2020 debatiendo las conclusiones presentadas por los distintos Grupos Parlamentarios y aprobando el correspondiente Dictamen $^{21}$. En sus quince sesiones, comparecieron distintos representantes

\footnotetext{
${ }^{20}$ Esa sensación de cierta euforia se transmitió por el presidente del Gobierno desde la tribuna del Congreso en el curso del debate de la última prórroga del estado de alarma, el 3 de junio de 2020.

${ }^{21}$ Disponible en:

https://www.congreso.es/web/guest/busqueda-de-

publicaciones?p_p_id=publicaciones\&p_p_lifecycle $=0 \& p \_p \_s t a t e=$ normal\&p_p_mode $=v i e w \& \_p$ ublicaciones_mode $=$ mostrarTextoIntegro\&_publicaciones_legislatura $=X I V \& \_p u b l i c a c i o n e s \_i d \_t$ exto $=(B O C G-14-D-130 . C O D I$.
} 
sociales y expertos. Si bien el tiempo de funcionamiento puede parecer demasiado breve para la dimensión de los objetivos, el resultado fue un ambicioso y largo Dictamen. Documento que debe entenderse como hoja de ruta del conjunto de las fuerzas políticas para los próximos años. Además, no fue el único resultado tangible de los trabajos de la Comisión. Junto a ese texto, es posible leer la amplia información aportada bien por los comparecientes directamente bien a través de distintos canales de participación ciudadana. En conjunto, la Comisión y, por ende, el Congreso aportó a la sociedad un notable aporte documental y una no menos relevante reflexión política. Así, podría decirse que, desde esta perspectiva, respondió a las necesidades del momento. Sin embargo, no creo que esta sea la sensación generalizada entre la sociedad. Son muy pocos los que conocen este trabajo y no parece que haya una percepción excesivamente positiva del conjunto del hacer Congreso sobre la epidemia ¿Cuál es la razón? Creo que intentar responder a esta pregunta suscita algunas de las cuestiones más relevantes a las que se enfrenta el Parlamento, y en alguna medida, la política contemporánea. En mi opinión, dos razones fundamentales explican por qué un trabajo objetivamente importante no ha tenido transcendencia. Por un lado, un evidente problema de comunicación. La sociedad no es consciente no ya del contenido del Dictamen aprobado por la Comisión sino de los resultados de su trabajo. Especialmente, se desconoce la importante documentación generada, en buena parte aportada por especialistas 0 representantes de sectores directamente afectados. Documentación relevante por si misma y, también, por lo que tiene de participación y presencia social en el Parlamento. Se trata de un problema recurrente de la institución. Es posible que el trabajo parlamentario no se corresponda con las exigencias del modelo social en cambio. Pero lo que es seguro es que lo que se hace, sustancialmente, se desconoce ${ }^{22}$.

La segunda razón que, creo, explica la inanidad del dictamen es cualitativamente más profunda. No se tiene la percepción de que las medidas contenidas en el mismo vayan a ser cumplidas. Entre quienes conocen su existencia, la convicción profunda es que se trata de un documento retórico, uno más. Un documento que, en principio, no tendrá consecuencias. Pasados cinco meses desde su aprobación, se puede decir que ese dictamen ha

\footnotetext{
${ }^{22}$ Sobre la relevancia de la comunicación en el Parlamento contemporáneo y las carencias que la acompañan tradicionalmente, TUDELA ARANDA, J., El Parlamento en tiempos críticos. Nuevos y viejos temas del Parlamento, Marcial Pons, 2020, pp. 84-87.
} 
desaparecido del debate público cuando, normalmente, debería haber sido una referencia. Así, lo lógico es que el mismo Parlamento controlase su cumplimiento. La impresión general es que, una vez más, primó la imagen sobre el fondo, la política de la oportunidad sobre la de la necesidad.

Siguiendo este modelo, en algunas Comunidades Autónomas se pusieron en marcha iniciativas similares con un protagonismo desigual de los respectivos Parlamentos, ya que en algunas como Comunidad Valenciana, Andalucía o Madrid se constituyeron Comisiones al modo del Congreso de los Diputados y en otras como Aragón o Castilla y León, se formalizaron grandes acuerdos sociales en los que si bien participaron los grupos parlamentarios, el Parlamento no fue sede de su elaboración. Pasados unos meses desde la efervescencia de este modelo, las pulsiones que se derivan de su aplicación remiten a esa sensación inicial de primacía de lo efectista sobre lo efectivo. En cualquier caso, el papel del Parlamento en las Comunidades Autónomas ha sido de perfil bajo. Y como tantas veces en la institución parlamentaria, llama sobremanera la atención el olvido en el que caen iniciativas de estas características una vez que han sido aprobadas, descuidando lo más relevante, su seguimiento y control.

Por último, en relación con el Congreso, es preciso llamar la atención sobre la omisión de una acción legislativa que parecía hubiese sido necesaria 0 , al menos, conveniente. Como se indicó, la situación provocada por la pandemia tenia singularidades que provocaban que las respuestas previstas en el ordenamiento, como poco, presentasen insuficiencias. Así, como sucedió en otros países, parecía razonable, y en este sentido se pronunció el propio Gobierno, que se impulsasen determinadas reformas legislativas con el objetivo de adaptarse mejor a una situación que si bien podía requerir de una afección intensa sobre los derechos y libertades, se alejaba de los presupuestos del estado de excepción. No se hizo. Así, es preciso constatar en el debe del Congreso esta omisión legislativa, aunque, bien se sabe, la responsabilidad última no se encuentre en el mismo.

Desde otra perspectiva, sorprende que los Parlamentos no dedicasen mayor atención a analizar lo sucedido. Las cifras que la primera ola de la pandemia había dejado en España eran particularmente dramáticas y dejaban en evidencia problemas de gestión objetivos. Parecía obligado y así lo reclamaron los científicos que comparecieron en la Comisión del Congreso, que se realizase un diagnóstico exhaustivo e independiente de lo sucedido. No se 
trataba sólo de diagnosticar errores y determinar eventuales responsabilidades. Saber lo que había sucedido era esencial para evitar que, al menos, una parte de esos problemas no se repitiesen en el futuro. En un futuro inmediato, ya que la epidemia seguía viva. No se realizó nada de ello. Ni siquiera en cuestiones que objetivamente reclamaban una respuesta urgente como la situación de las residencias de ancianos y, en general, la asistencia a mayores; o la provisión de material al personal sanitario; o la coordinación de las relaciones entre las distintas administraciones públicas; o el estudio de las debilidades del modelo sanitario frente a una situación como esta, por poner sólo algunos ejemplos evidentes, merecieron esa reflexión. Cuando se intenta comprender por qué los ciudadanos están distanciados del Parlamento o, simplemente, le niegan utilidad, considerando mayoritariamente que es una institución inane, en demasiadas ocasiones se omite la respuesta más simple. El silencio de estos meses ante estos temas es parte de esa respuesta. Esa tarea de diagnóstico y eventual delimitación de responsabilidades es una tarea netamente parlamentaria. Más. Es el papel que le corresponde al Parlamento en una crisis como la vivida. Dieciocho Parlamentos, dieciocho silencios. Y lo más significativo es que, en general, la causa no ha sido la resistencia de la mayoría, cercenando las correspondientes iniciativas de la oposición. Lo preocupante es que ni siquiera han existido las iniciativas adecuadas para poder plantear un debate inexcusable. Un hecho que transciende el análisis de esta coyuntura, incluso el del funcionamiento de la institución parlamentaria para contaminar negativamente el juicio sobre la acción política en nuestro País. En todo caso, avanzo, no creo que el Parlamento pueda eludir definitivamente esta tarea.

Junto a lo anterior, una vez finalizada la primera alarma, el trabajo parlamentario debía centrarse en fijar la atención en la evolución de la covid19. En este caso, concluida también la centralización de mando aneja al estado de alarma y reestablecido plenamente el ejercicio ordinario de las competencias, el protagonismo pasaba a descansar en los Parlamentos autonómico $^{23}$. Lógicamente, su actividad fue diversa, cambiando en función, básicamente, de la evolución de la pandemia en cada Comunidad Autónoma. Así, en algunas Comunidades el tiempo de relajación fue mayor mientras que

${ }^{23}$ En este punto, es preciso reflexionar sobre lo sorpresivo que resulta que cuando la epidemia si bien controlada se encontraba aún viva (y con todas las previsiones apuntando a su regreso en un plazo más o menos inmediato), no se estableciese un régimen transitorio durante el cual el Gobierno retuviese significativas funciones de coordinación. 
en otras como Cataluña o Aragón, apenas hubo tiempo para ello, ya que la denominada segunda ola comenzó muy rápidamente. Durante este tiempo y con la diversidad mencionada, los ejecutivos autonómicos tuvieron que hacer frente a situaciones en ocasiones muy complicadas sin el amparo jurídico del estado de alarma. La consecuencia fue que las normas que aprobaron, mayoritariamente reglamentarias y necesariamente restrictivas de derechos, fuesen en muchos casos cuestionadas ante los tribunales, con resultados diferentes. Así, el debate se alejó del Parlamento para centrarse en los tribunales. El papel de los Parlamentos autonómicos quedó reducido a la aprobación en algún caso de Decretos-Leyes que pretendían salvar los problemas planteados por la naturaleza reglamentaria de las normas aprobadas hasta ese momento y a una tibia labor de control, siguiendo los procedimientos e instrumentos ordinarios ${ }^{24}$. En este sentido, llama la atención la incapacidad para singularizar la respuesta. Los Parlamentos bien podían haber ideado la forma para desempeñar con más eficacia su imprescindible tarea de seguimiento y control. Una vez más, se careció de reflejos, incumpliendo funciones esenciales y perdiendo una oportunidad más para hacer efectivo el principio de representatividad.

\section{III.LOS HECHOS (II). LA SEGUNDA ALARMA. EL PARLAMENTO DORMIDO}

A finales del verano y principios del otoño, se observó un agravamiento de la epidemia, creciendo de forma preocupante el número de hospitalizados e ingresados en la $\mathrm{UCI}$. La insuficiencia de recursos normativos de las Comunidades Autónomas era evidente desde hace tiempo. No habiéndose realizado modificación alguna en la legislación ordinaria, se hizo preciso regresar a la senda de la excepción. Así, el 25 de octubre el Gobierno declaró el estado de alarma en todo el territorio nacional. El correspondiente plazo de quince días finalizó el 9 de noviembre y, con anterioridad, en concreto el 3 de noviembre, aprobó la solicitud de prórroga del mismo hasta el 9 de mayo de 2021 , es decir por un periodo de seis meses. La prórroga de seis meses fue autorizada por el Congreso de los Diputados por una amplia mayoría, con el voto en contra del Grupo Parlamentario de Vox y la abstención del Grupo

\footnotetext{
${ }^{24}$ Uno de los ejemplos más significativos fue el Decreto-Ley $7 / 2020$, de 19 de octubre, del Gobierno de Aragón, por el que se establece el régimen jurídico de alerta sanitaria para el control de la pandemia Covid-19 en Aragón.
} 
Parlamentario Popular. Junto a este plazo, lo más relevante de la nueva declaración era el giro que se daba en relación con el modelo de gestión territorial. Si en el primer estado de alarma, la característica fue el mando único, reduciendo el papel de las Comunidades Autónomas a meros receptores cualificados de información, en este nuevo periodo, se olvidaba el mando único y se delegaba en el Presidente de cada Comunidad Autónoma la condición de autoridad competente.

Las dos cuestiones exigen un comentario detenido y lo tienen en el volumen que el lector tiene en sus manos. En estas páginas, me limitaré a examinar la relación entre el Parlamento y el estado de alarma en las condiciones establecidas en esta segunda declaración. Un examen que se realizará con independencia de la idoneidad constitucional de las mismas. En todo caso, es preciso realizar una breve reflexión general sobre los dos aspectos señalados. En relación con el plazo, creo que es preciso decir que el mero hecho de que ni la Constitución ni la Ley Orgánica establezcan un límite expreso a la duración de la prórroga de los estados de alarma, no significa que ese límite no exista. La situación de alarma es, por definición, excepcional y las dudas jurídicas que se planteen sobre la misma deben resolverse de forma sistemática utilizando el conjunto de principios derivados de la Constitución. Así, creo que se puede afirmar que, en todo caso, un plazo de seis meses sin intervención del Parlamento resulta problemático y que obliga a la reflexión. Desde su solicitud, se abrió un debate centrado en su posible inconstitucionalidad. La ya aludida ausencia de un límite temporal expreso fue el principal argumento utilizado para defender su legalidad. Por el contrario, aquellos que alegan su inconstitucionalidad lo hacen sobre la presunción de que el plazo de la prórroga no podría superar al plazo máximo que la Constitución habilita para la declaración. Junto a ello, se esgrimen principios como el de proporcionalidad y la teoría general del control del poder en un estado excepcional de concentración del mismo ${ }^{25}$. En páginas inmediatas intentaré responder a esta cuestión exclusivamente desde la perspectiva del deber ser y estar de la institución parlamentaria en nuestro sistema constitucional. También es preciso recordar que, según declaraciones de miembros del Gobierno, la razón última de un periodo tan largo es la dificultad para alcanzar la correspondiente mayoría en el Parlamento. Indiqué en su momento que la inexistencia de esa

\footnotetext{
${ }^{25}$ Sobre la necesidad de acomodar las sucesivas prórrogas del estado de alarma a los quince días previstos para la primera, ARAGÓN REYES, M., "Epílogo", en Los efectos horizontales de la Covid-19 sobre el sistema constitucional: estudios sobre la primera oleada, ob. cit.
} 
mayoría explicaba la visión del Gobierno hacia el Parlamento durante la primera crisis. En la condición de normalidad que presupone el régimen parlamentario, una mayoría estable sosteniendo al Gobierno, la mirada y relación con el Parlamento habría sido otra. Es comprensible que sin esa mayoría el Gobierno sea más renuente a establecer determinadas relaciones con el Parlamento. Pero cuando le lleva a evitar relaciones necesarias, la cuestión transciende la mera oportunidad política para devenir un problema jurídico constitucional.

La segunda cuestión, la gestión territorial de la alarma, también, como se verá, interesa y mucho al Parlamento. Pero antes de entrar en las cuestiones que suscita, es preciso llamar la atención sobre el antagonismo de las dos decisiones adoptadas en esta materia. De una centralización absoluta, reflejada en la figura del mando único y reiteradamente visibilizada en la figura del Presidente del Gobierno, se ha pasado a un modelo de gestión delegada, con desaparición efectiva del Gobierno de la Nación. En medio, un puente de confusión y desorden, marcado por las exigencias de las formaciones nacionalistas y las insuficiencias de las Comunidades para hacer frente con sus instrumentos normativos a las necesidades derivadas de la epidemia. A día de hoy, nadie ha explicado este cambio radical de criterio. En las páginas que siguen, se examinará cómo afecta lo establecido en el segundo estado de alarma al Parlamento. Pero no puedo dejar de constatar que, más allá del dudoso rigor que se pueda adjudicar a este marco jurídico ${ }^{26}$, esta dualidad no habla especialmente bien del diseño territorial. Sólo la ausencia de unas mínimas coordenadas en el modelo de relaciones intergubernamentales puede explicar una transición tan radical entre dos modelos que, como se observó en su momento y se está demostrando en el presente, son necesariamente defectuosos. De hecho, sorprende que la mera existencia de los dos modelos no haya sido por sí sola objeto de una profunda reflexión y, en su caso, crítica.

En relación con el plazo de seis meses, lo relevante para el Parlamento es que se queda sin capacidad de incidir en las condiciones de la alarma, incluso de

\footnotetext{
${ }^{26}$ Los argumentos para sostener la inconstitucionalidad de este modelo son consistentes. Un modelo que no delega en los Gobiernos, sino en los Presidentes. Tanto por la propia naturaleza de los estados de excepción cuya gestión parece necesariamente vinculada al Gobierno de la Nación como por la afección directa e intensa a derechos y libertades, como por las dificultades directamente relacionadas con la institución de la delegación (¿Qué sucede con los posibles recursos?), las dudas jurídicas se extienden (Ver al respecto por su especial claridad, TAJADURA TEJADA, J., "Estado de alarma y seguridad jurídica", El País, 27 de octubre de 2020).
} 
revertir la misma durante un plazo objetivamente muy largo. $Y$ en este punto es forzoso realizar una aclaración. Por supuesto, ello no significa que durante esos seis meses el Parlamento no pueda controlar sobre este punto al Gobierno o solicitar toda la información necesaria. La declaración del estado de alarma no altera el normal funcionamiento del Congreso y el ejercicio en plenitud de sus funciones, muy en particular la de control. Esta aclaración es particularmente precisa porque la distinción entre la función ordinaria de control y la actuación extraordinaria en relación con el estado de alarma es el presupuesto necesario para comprender bien la posición de las Cortes Generales en esta situación. Pero también porque se ha extendido, desde el mismo texto del Real Decreto de declaración del estado de alarma, que lo que es mera función ordinaria de control o, incluso mera información al Parlamento, se pueda equiparar a una intervención extraordinaria del Congreso en relación con la declaración, suficiente como para avalar el plazo de seis meses. Inmediatamente me extenderé en este punto. La premisa inexcusable es que el control del Gobierno durante la vigencia del estado de alarma nada tiene que ver con la posición que corresponde al Congreso ex artículo 116 de la Constitución y que es lo que únicamente se dirime en este punto.

Resulta preciso extenderse sobre la comprensión de las relaciones Gobierno/Congreso que parece anidar detrás de la regulación de lo que el Real Decreto 976/2020, y la solicitud de prórroga correspondiente, denominan "Rendición de cuentas", a la que se dedica el artículo 14. En la redacción del Real Decreto, el artículo citado se limitaba a señalar que "en caso de prórroga, el Ministro de Sanidad comparecerá quincenalmente ante la Comisión de Sanidad y Consumo del Congreso de los Diputados para dar cuenta de la aplicación de las medidas previstas en este real decreto". Este artículo fue uno de los que se enmendó en el Congreso, como contrapartida para obtener el voto favorable de alguno de los Grupos de la oposición. En su redacción final, se establece en mensual el plazo de las comparecencias del Ministro y se fija que cada dos meses el Presidente del Gobierno solicitará la comparecencia ante el Congreso de los Diputados "para dar cuenta de los datos y gestiones del Gobierno de España en relación a la aplicación del Estado de Alarma". Me parece una secuencia significativa que ayuda mucho a comprender y valorar el papel del Congreso en la crisis.

En mi opinión, no se ha llegado a reparar suficientemente en el alcance de la redacción originaria. Más allá de la suficiencia o insuficiencia de su contenido, 
lo que llama poderosamente la atención es que el Gobierno se arrogue la capacidad de determinar cuándo y dónde comparecerá el Ministro. Ello sólo se puede explicar por el error ya mencionado de confundir la función ordinaria de control con la intervención del Congreso en relación con el estado de alarma. La redacción final no altera demasiado este presupuesto. En su momento, algunos vieron en el compromiso adquirido por el Congreso una conquista parlamentaria. De nuevo, rige la confusión mencionada. Pero, con todo, lo más inquietante es que de esta normativa parece deducirse que es el Gobierno quien determina la forma y "cantidad" del control. El Parlamento renuncia a su iniciativa en esta materia y acepta aquello que el Gobierno tiene a bien conceder. De acuerdo con el citado artículo 14 ¿hay que entender que el Parlamento se ha comprometido a no solicitar la comparecencia ni del Ministro de Sanidad ni del Presidente del Gobierno fuera de los términos allí establecidos? En principio, la respuesta parece afirmativa. Al menos, parece existir el compromiso. Cuestión diferente es que, obviamente, el Congreso, algunas de las formaciones políticas que lo integran, puedan intentar alterar ese ritmo. Pero ello no resta gravedad al axioma que subyace a este planteamiento. Para el Gobierno y para el propio Congreso, es al Gobierno a quién corresponde determinar cómo se ejerce el control. Evidentemente, una conclusión aún más grave cuando se trata de determinar el control en una situación de poder excepcional que exigiría de un Parlamento reforzado. Siempre cabe reprochar a un Gobierno que no sea respetuoso con el Parlamento. Pero es mucho más grave que el propio Parlamento no se respete a si mismo. En este sentido, y es una de las conclusiones más relevantes que se pueden extraer, el Congreso de los Diputados ha demostrado tener en poca estima el ejercicio de sus funciones. No se puede llegar a otra conclusión si a esta aceptación de las reglas del juego sobre el control ordinario se suma la aceptación de los seis meses de prórroga.

Seis meses es un plazo muy largo y la reducción de competencias del Parlamento, muy relevante. No analizo si es constitucional o no, aunque, cuando menos, es objetivo que plantea muy serias dudas analizado desde el principio de proporcionalidad y desde el necesario análisis sistemático de la Constitución. Me limito a examinar el plazo en el marco de las relaciones entre Parlamento y Gobierno que son propias de la forma parlamentaria y de las funciones del primero. El juicio se agrava si se tiene en cuenta la transcendencia de la situación y esa función de liderazgo social que, en 
principio, cabría atribuirle a la institución parlamentaria. Junto a ello, también son agravante las dudas jurídicas mencionadas. Seis meses es un plazo exorbitante. Suficiente como para que el Parlamento, lejos de retraerse, hubiese sido particularmente celoso para defender su posición y funciones. Como se ha visto, no sucedió. Los grupos parlamentarios aceptaron mayoritariamente la propuesta del Gobierno y los órganos rectores de la Cámara no hicieron movimiento alguno en defensa de los intereses de la institución ${ }^{27}$. El Parlamento aceptó como normal lo excepcional. No sólo eso. Aceptó determinar previamente y de forma pactada el ejercicio del control que le correspondía durante esos seis meses.

Un apunte adicional debe realizarse sobre la disfuncionalidad de un plazo tan largo para la propia gestión de la pandemia, como demuestra el debate generado en las primeras semanas de enero sobre un posible adelanto de la hora del toque de queda que la alarma vigente establece a las 22 horas. Ante un notable agravamiento de la situación sanitaria, un muy amplio número de Comunidades Autónomas reclamaron oficial y oficiosamente la posibilidad de adelantar la hora del toque de queda a las 20 h. o, incluso, a las $18 \mathrm{~h}$. Castilla y León, contraviniendo con claridad la letra del Real Decreto, la adelantó a las 20 horas ${ }^{28}$. El Gobierno rechazó estas peticiones, aduciendo que las Comunidades ya tenían instrumentos suficientes para luchar contra la pandemia. Más allá de cualquier juicio de oportunidad, lo evidente es que la situación sanitaria era muy diferente a cuando se aprobó ese texto y que, además, se ha establecido que sean las Comunidades Autónomas quienes valoren las circunstancias y actúen en consecuencia. Es claro que la letra del Real Decreto plantea limitaciones objetivas a esa gestión. Como lo es que el hecho de no ser prorrogado cada quince días dificulta sobremanera su adecuación a unas circunstancias necesariamente cambiantes.

He mencionado que también el nuevo modelo de gestión territorial que establece el Real Decreto 926/2020 incide en el trabajo parlamentario. Se

\footnotetext{
${ }^{27}$ Por más que se esté acostumbrado a la subordinación de los órganos rectores del Parlamento a los criterios de la formación que en la práctica les designó, no debe dejar de repararse en ello. Sin aspirar a modelos ideales de independencia, creo que sería exigible que se salvaguardase un mínimo de autonomía institucional que permitiese alejar a la institución de la imagen de un mero apéndice de las necesidades y conveniencias del ejecutivo. En unas circunstancias como las que son sustrato de este trabajo, ello se ha puesto de relieve con especial intensidad.

${ }_{28}^{28}$ VIDAL PRADO, P., "La Covid es letal pero seguimos en un Estado de derecho", El Norte de Castilla, 16 de enero de 2021, disponible en https://www.elnortedecastilla.es/opinion/covid-letalseguimos-20210116184128-nt.html
} 
cambia radicalmente el modelo y la competencia de la pandemia se delega en los Presidentes de las Comunidades Autónomas. Más allá de las medidas contenidas en el texto del Real Decreto, y cuya modulación corresponde a las Comunidades Autónomas, el Gobierno de la Nación parece desaparecer de la gestión de esta etapa. La consecuencia desde el análisis del trabajo parlamentario es obvia. Una parte significativa del control dejará de ser ejercida por las Cortes Generales para ser realizado por los Parlamentos autonómicos. En páginas sucesivas analizaré la situación. En todo caso, creo que la mencionada alteración de las competencias de gestión no significa que las Cortes Generales casi pasen por necesidad a la omisión. Con todo, su función de control en esta materia debe ser muy relevante. La delegación de la gestión en las Comunidades Autónomas no debe entenderse como irresponsabilidad del delegante. Es más, este análisis acerca a una de las cuestiones más conflictivas de la gestión de la pandemia y, por ende, más susceptible de crítica e intervención parlamentaria. Me refiero a la mencionada disparidad de modelos que plantean las dos declaraciones de estado de alarma y, en particular, la retirada del Gobierno de la Nación en el segundo de ellos.

La pandemia no ha sido sólo un reto para el modelo territorial, en particular para la distribución de competencias y las relaciones intergubernamentales. También ha planteado por vez primera un desafío conjunto a las Cortes Generales y a los Parlamentos Autonómicos. Con más claridad que nunca, la multiplicidad de escenarios parlamentarios ha adquirido plena funcionalidad. La representatividad política y el control del poder en una situación de excepción debería ser la suma de lo sucedido en todos los Parlamentos. A su vez, cada uno de ellos es un altavoz de la Información más necesaria en la crisis. Es pronto para valorar cómo se ha respondido a este desafío. Sí se puede decir que en ningún caso se ha trabajado por coordinar respuestas y que el juicio final será el resultante de la suma del trabajo de las partes.

\section{LOS PARLAMENTOS AUTONÓMICOS EN LA TERCERA FASE}

Con brevedad, es preciso cerrar el examen de las relaciones Parlamento/estado de alarma durante la pandemia haciendo una referencia específica a los Parlamentos autonómicos durante la segunda declaración. La vis atractiva de la Cortes Generales suele monopolizar la visión de la realidad parlamentaria en España. Como reitero siempre que tengo ocasión, ello es un 
error. Es evidente que las Cortes Generales, y en particular el Congreso, protagonizan una buena parte del debate político. Sin embargo, desde el análisis del rol que corresponde desempeñar a la institución parlamentaria en un Estado descentralizado, el estudio de los Parlamentos autonómicos es imprescindible. Precisamente, creo que una de las lecciones que para el conjunto del sistema constitucional se pueden extraer de lo acaecido durante estos meses, es que resulta preciso dimensionar adecuadamente la posición de estas instituciones. Lo sucedido durante toda la pandemia, en la que, no se olvide, una materia sobre la que las Comunidades Autónomas tienen la competencia exclusiva ha sido protagonista, avalaría sin más esta afirmación. Si ello no fuera suficiente, la delegación de la decisión sobre la gestión durante la segunda alarma, ratifica definitivamente este aserto.

De forma inmediata, la segunda consideración general a la que enfrenta esta situación es, de nuevo, a la distinción entre control sobre el estado de alarma y control parlamentario de lo sucedido durante el estado de alarma. Como se explicó en su momento, con el Real Decreto 976/2020 y su prórroga, incluso los propios grupos parlamentarios, cayeron en confundir ambos extremos, distorsionando, simultáneamente, los dos. La dejación de la responsabilidad de mando por parte del Gobierno de la Nación tiene, lógicamente, unas consecuencias relevantes sobre la acción de los Parlamentos. Así, en primer lugar, se provoca una escisión entre el control estricto de la alarma y el control de la gestión de la pandemia. Si el primero correspondería a las Cortes Generales y, en concreto, al Congreso, el segundo recaería sobre los Parlamentos autonómicos, aunque, obviamente, las Cortes Generales puedan seguir ejerciendo el control que consideren preciso sobre el Gobierno. Como señalé, en la práctica, debido a la prórroga por seis meses de la alarma, ello significa que se aletarga muy notablemente la capacidad de acción de las Cortes Generales durante esta segunda alarma. De hecho, el protagonismo del control político de la misma pasa a corresponder a los Parlamentos autonómicos. Dada la relevancia de la situación, se puede considerar que esta situación supone una verdadera prueba de fuego para los mismos. En el momento de escribir estas líneas, diciembre 2020/enero 2021, es imposible realizar un balance riguroso. En todo caso, es factible aproximarse a un deber ser y reflexionar sobre las lecciones que se pueden extraer de esta situación.

Antes de examinar ese deber ser, resulta preciso detenerse en la visión de conjunto que depara la escisión comentada anteriormente. Creo que, con 
independencia de lo que pueda suceder en meses venideros, hay una dilución del control político de la gestión de la pandemia y del uso de los poderes extraordinarios derivados de la misma. No se trata sólo de la objetiva marginación del Parlamento en relación con la declaración y modulación de la alarma, cuestión ya de por si muy relevante. Ni siquiera la cuasi autolimitación del Congreso en relación con el control de la gestión de la pandemia. Es que la variante de la gestión territorial añade un factor de confusión y, por qué no decirlo, de debilidad. Es posible que el tiempo desmienta temores y los Parlamentos autonómicos cumplan con eficacia su labor de control. Pero los antecedentes no invitan a ser optimistas. Si la eficacia no caracteriza el ejercicio de esta función en el Congreso, menos lo hace en los Parlamentos autonómicos $^{29}$. Distintas circunstancias lo explican. El mayor peso del ejecutivo y una aún más notable presidencialización del sistema; la, normalmente, mayor debilidad de la oposición; la carencia de medios materiales para desempeñar con eficacia la función; o la menor atención mediática, serían sólo algunos de los elementos que explican esta debilidad. Por lo demás, el trabajo realizado en relación con lo sucedido durante la primera fase y el tiempo de transición, no ayuda a la confianza. Cuestiones centrales, directamente responsabilidad de las Comunidades, como la gestión sanitaria básica; abastecimiento de material al personal de riesgo; o el desempeño de las residencias de mayores, no han tenido en los Parlamentos autonómicos el eco que parecía obligado. Así, es difícil evitar el escepticismo en relación con unos meses en los que, resulta preciso reiterarlo, las Comunidades van a tener un protagonismo cuasi absoluto en relación con la gestión de la pandemia.

En efecto, la posición de los Parlamentos autonómicos en esta etapa puede calificarse de absoluta centralidad. En ellos, deberá encontrar el ciudadano aquello que siempre debe significar y ofrecer un Parlamento. Es conveniente recordarlo porque no parece que haya sido tenido demasiado en cuenta durante estos meses. El Parlamento es, por supuesto, el espacio en el que la oposición controla al Gobierno. Y ello significa, nadie debería escandalizarse por ello, señalar responsabilidades y errores de gestión. Una tarea que en un buen entendimiento del sistema político es esencial para su rectificación y mejora del conjunto de la acción política. Pero, y también se dijo, la acción de la oposición en el Parlamento es también la mejor forma que tienen los

\footnotetext{
${ }^{29}$ Véase, PANIAGUA, J. L., "Los estudios sobre el Parlamento y el control parlamentario: una aproximación desde la ciencia política", en Los Parlamentos autonómicos en tiempos de crisis, ob. cit., pp. 87-140.
} 
ciudadanos de enjuiciar su labor para premiarla y/o castigarla. Si se cae en la irresponsabilidad, que nadie se preocupe. Serán los ciudadanos quienes actúen en consecuencia. Pero el Parlamento es más. Es también, y de manera notable, el escenario, el locus por excelencia en el que el Gobierno debe argumentar y, también realizar la correspondiente pedagogía ciudadana. Es decir, ejercer el liderazgo que le corresponde. Ni que decir tiene que ello en un tiempo crítico como el descrito, resulta esencial. Si a ello se suman dos cualidades netamente parlamentarias como la publicidad y la deliberación, se podrá comprender con claridad la síntesis de aquello que la institución debe ofrecer a los ciudadanos. Liderazgo y referencia. Los ciudadanos deben poder confiar en que sus dirigentes políticos a través de la institución central y, por definición, plural del sistema, les transmiten, al menos, la confianza de la capacidad para generar respuestas a los desafíos que se plantean.

Como indiqué, no es posible en este momento estudiar siquiera la acción de estos Parlamentos durante esta crisis. Por ello, el planteamiento se traslada al deber ser ¿cómo debieran desenvolverse para poder escribir dentro de unos meses una crónica venturosa?

Lógicamente, la respuesta debe adaptarse a las circunstancias de cada Comunidad Autónoma. La cultura política y factores como el sistema de partidos, la estabilidad de la mayoría de gobierno o la tradición parlamentaria, la condicionarán. Pero si nos trasladamos al territorio del deber ser, hay más posibilidades de encontrar una mínima homogeneidad. El presupuesto debiera ser un comportamiento equilibrado tanto del Gobierno y de los grupos que lo sostienen como de la oposición. En tiempos de normalidad, apelar al equilibrio y racionalidad del comportamiento político puede ser un exceso ante el posible conflicto con los inmediatos intereses políticos. Sin embargo, no es un tiempo normal. La gravedad de la situación obliga con especial intensidad a los distintos agentes. Así, el diálogo debe ser una constante completada con el mutuo respeto a las posiciones de cada cual. A los gobiernos les corresponde asumir la responsabilidad de gobernar $y$, en consecuencia, aceptar la posibilidad del error y, por supuesto, de la crítica y de la divergencia, y a la oposición le corresponde controlar, pero sin olvidar las exigencias derivadas de lo excepcional de la situación. Desde estas premisas, el Parlamento debe desplegarse en plenitud.

En primer lugar, su hacer debe pensarse y programarse en relación con aquello que los ciudadanos esperan de sus políticos en una situación 
semejante. La empatía siempre es una cualidad valiosa. En un político, resulta imprescindible. Cuando la sociedad se encuentra dominada por la incertidumbre, sino directamente por el miedo, es obligación de los representantes políticos intentar paliar ese desasosiego. Desde el Parlamento ello se traduce no sólo en la adopción de determinadas medidas. También en su dimensión de foro de deliberación y comunicación. El hemiciclo es el gran escenario político. Un lugar privilegiado para que los diputados y miembros del gobierno transmitan a la ciudadanía el mensaje de que si bien la situación es difícil, existe la respuesta política. El lugar desde el que se debe ser capaz de generar una mínima dosis de confianza.

En segundo lugar, y desarrollando la idea anterior, es obligación de los Parlamentos, y, en concreto, de los Parlamentos autonómicos, adaptar su agenda a esta circunstancia. Pienso, en concreto, en tres medidas. En primer lugar, la programación de sesiones específicas y periódicas de pleno y comisión para tratar esta cuestión. En segundo lugar, un cuidado particular de los órdenes del día. Por supuesto, el Parlamento tiene que seguir tratando otros temas y ejerciendo en plenitud sus funciones. Pero no puede ser ajeno al cuasi monopolio que la pandemia y sus consecuencias ejercen en la vida cotidiana. En tercer lugar, y por último, debería pensarse la forma de facilitar una participación constante de los distintos agentes sociales para que, al menos, puedan tener la certidumbre de que el poder les escucha y es conocedor de sus problemas. El trabajo parlamentario debe adaptarse a la situación excepcional que se vive. Sería muy grave que los ciudadanos perciban que, una vez más, las instituciones, y en concreto el Parlamento, se encuentran lejos de la realidad y se esconden detrás de debates que por más relevantes que pudieran ser, han dejado de ser prioritarios ante lo inmediato.

En tercer lugar, en todos los Parlamentos debería habilitarse una comisión especial de seguimiento en relación con los efectos de la pandemia. Una comisión que tendría que centrar su atención en dos cuestiones fundamentales. Por un lado, la perspectiva socio sanitaria y las exigencias derivadas de la misma. Por otro, las consecuencias socio económicas. En aquellas Comunidades en las que se elaboró un plan de reconstrucción, sería función adicional de esta comisión controlar e impulsar su puesta en marcha. Creo que no hay que explicar su utilidad. Alguien puede alegar que sus funciones pueden ser desempeñadas, incluso mejor, de forma sectorial. Creo 
que no existe incompatibilidad sino complementariedad. Además, su existencia tendría sin duda un impacto positivo en la ciudadanía.

Finalmente, los Parlamentos deben revisar su trabajo durante estos meses desde las premisas del Parlamento abierto que de forma incipiente habían comenzado a interiorizarse ${ }^{30}$. Es un momento excelente para ello. Se necesitan respuestas políticas y el Parlamento es espacio idóneo para facilitarlas. De esta manera, el acceso a la información; la participación y la transparencia deberían ser bandera del quehacer parlamentario en este tiempo. Información, participación y transparencia que deben ser interpretados de forma ambiciosa. El Parlamento puede y debe intentar convertirse en un núcleo informativo esencial en relación con la pandemia. Por supuesto, se encontrará con la reticencia del ejecutivo. Pero una lectura adecuada tanto de las exigencias institucionales como de las necesidades sociales, concluye en que para los gobiernos, el protagonismo informativo y participativo del Parlamento más que desventaja puede ser una ayuda indispensable. Las consecuencias de la epidemia pueden tener efectos devastadores sobre el tejido social y resulta preciso prever institucionalmente la situación ofreciendo desde el principio desagües a través de los cuales al menos se pueda diluir una parte de la inevitable frustración individual y colectiva. Así, se debería programar un ambicioso calendario de comparecencias de los colectivos más afectados. El objetivo no sería sólo tener la oportunidad de escuchar sus problemas y sugerencias. También transmitir empatía y dar protagonismo al Parlamento en el debate público.

Por supuesto, podría hacerse referencia a otras cuestiones, como el ejercicio de la función de control a través de los instrumentos ordinarios. Es lo único que seguro se hará. En los distintos Parlamentos se tramitarán preguntas, solicitudes de comparecencia, interpelaciones e, incluso, alguna comisión de investigación. No hay nada que objetar. Pero lo que he querido destacar es que si no se asume la premisa de la excepcionalidad de la situación, y se actúa en consecuencia, adaptando de forma global el trabajo de la institución, se correrá el riesgo evidente de defraudar las expectativas de los ciudadanos y, en todo caso, de no responder a sus necesidades.

\footnotetext{
${ }^{30}$ Al respecto, RUBIO NÚÑEZ, R. y VELA NAVARRO-RUBIO R., El Parlamento abierto en el mundo. Evolución y buenas prácticas, Fundación Manuel Giménez Abad, 2017; TUDELA ARANDA, J., El Parlamento en tiempos críticos. Viejos y nuevos problemas del Parlamento, ob. cit., pp. 139-162.
} 
Finalmente, es preciso reiterar que el protagonismo que necesariamente recae en los Parlamentos autonómicos como consecuencia de la ordenación territorial de la gestión de la pandemia en esta segunda fase, en absoluto es óbice para que el Congreso de los Diputados ejerza el control sobre el Gobierno de la Nación. No es sencillo tener una dimensión exacta del alcance jurídico (ni político) de la citada delegación. Lo que creo que es obvio es que no limita la responsabilidad política del Gobierno de la Nación, incluyendo las posibles consecuencias de la propia delegación. Así, hay que esperar y exigir que el Congreso ocupe el espacio político que le corresponde y para ello requerirá de algo más que el cumplimiento estricto de las previsiones de comparecencia del Ministro de Sanidad y del Presidente del Gobierno. Por lo demás, junto al control del presente, su rol en esta complicada dinámica institucional sigue anudada tanto a lo sucedido en meses anteriores como a la adopción de las correspondientes medidas tanto para prevenir en lo sanitario como paliar y compensar los daños económicos y sociales.

\section{CONCLUSIÓN. UNA OPORTUNIDAD PERDIDA}

Las consideraciones conclusivas sobre la situación descrita en las páginas precedentes se pueden abordar desde perspectivas muy diversas. Se podría realizar un ejercicio de síntesis y valorativo sobre el comportamiento de los distintos Parlamentos españoles, destacando, como es lógico, el rol del Congreso de los Diputados. También podría reflexionarse sobre los retos que para el futuro ha dibujado esta situación, no siendo los menos relevantes los logísticos. O realizar un ejercicio de deber ser, de nostalgia por lo no sucedido. Será inevitable que en las escasas líneas en las que desarrolle esta conclusión, haya un poco de todo. Pero intentaré que prime una idea fundamental. El triste papel que nuestros actores políticos, incluyendo los parlamentarios, asignan a la institución en la dinámica política.

Como punto de partida, debe admitirse la excepcionalidad de la situación. Nadie estaba preparado para un confinamiento casi absoluto de dos meses. Es normal que, al menos durante dos semanas, la perplejidad alcanzase también a los Parlamentos. Si a ello se suma su debilidad material para hacer frente a la situación, la casi total ausencia de esos días puede entenderse. Pero inmediatamente hay que decir que es menos comprensible la tardanza en la reacción. Es menos comprensible que no se asumiese que el trabajo 
parlamentario era tan esencial como otros que estaban exigiendo una presencialidad que nadie discutía y que ello era así porque, precisamente, en una situación como la que se vivía, el Parlamento era más necesario que nunca. Como contrapoder del ejecutivo, por supuesto. Pero también como como foro desde el que todas las formaciones, incluido el ejecutivo, se dirigiesen a la sociedad transmitiendo la información y dosis de tranquilidad precisas. No se entendió así. Al menos, no se llevó esa conclusión a las consecuencias que parecían derivarse de la misma y, en general, se optó por un desempeño débil de las funciones parlamentarias.

Y en fase conclusiva resulta inevitable destacar que ello, lejos de corregirse, se radicalizó con el tiempo. Durante la segunda declaración del estado de alarma, el desempeño del Parlamento es aún mucho más débil. Con independencia de las dudas razonables de constitucionalidad que plantea una prórroga de seis meses, lo que resulta difícil de objetar es su poca coherencia con el valor que el control político tiene en una situación de excepcionalidad. Creo que no hay mejor prueba del algodón para afirmar esta objeción que pensar que es lo que afirmarían quienes han apoyado su declaración si hubiesen estado en la oposición. Más allá, es indiscutible que ese plazo cercena radicalmente la posibilidad del Parlamento de posicionarse periódicamente sobre un instrumento con valor de ley. Ni siquiera un cambio sustancial de las circunstancias permitiría que el Congreso dispusiese de iniciativa en este sentido.

Como he reiterado, el ejercicio ordinario de la función de control no puede mezclarse con esa amputación de una presencia necesaria del Parlamento. El control del día a día del ejecutivo, incluyendo las cuestiones relacionadas con la alarma, es independiente de la autorización debida a las prórrogas de la alarma. Por supuesto, no corresponde al Gobierno determinar cómo y en qué condiciones se ejercerá esa función. Por otra parte, las consecuencias en uno y otro caso son radicalmente diferentes. Entre otras, para lograr la prórroga de la alarma el Gobierno necesita de una mayoría parlamentaria que no precisa por el ejercicio de los instrumentos ordinarios de control. Esta y no otra parece la única explicación posible al plazo de seis meses.

No debe omitirse que se ha llegado a esta situación sin apenas resistencia por el Parlamento. Los órganos rectores del Congreso no han realizado acción alguna en defensa de la posición de la institución. Por otra parte, la gran mayoría de los grupos parlamentarios han aceptado, con más o menos 
entusiasmo, el planteamiento del Gobierno. $Y$ debe repetirse que ha sido parte del mismo establecer la forma en la que diputados y grupos deberán ejercer el control. Es más, el gran logro que obtuvieron algunos de ellos a cambio de avalar el plazo de seis meses fue la previsión de dos comparecencias del Presidente del Gobierno para informar de la gestión. ¿Debe entenderse que de esta manera están renunciando a otras comparecencias o a cualquier fórmula adicional de control? ¿Debe entender el Gobierno que no se encuentra comprometido ante el Congreso más allá de lo establecido en el Decreto del estado de alarma?

En este punto, resulta necesario llamar la atención sobre la gravedad de lo sucedido durante el mes de enero de 2021. Durante este mes, la evolución de la pandemia se agravó considerablemente por, al parecer, la confluencia de los comportamientos durante las navidades y la emergencia de nuevas cepas más agresivas. De hecho, se regresó a una situación similar a la que produjo el confinamiento durante la primavera de 2020. Junto a ello, en esos días se inició la campaña de vacunación. En estas circunstancias, ni el Senado, ni muy especialmente el Congreso, tuvieron a bien habilitar sesiones ni de pleno ni de comisión para realizar un mínimo seguimiento. Se habilitaron para otros temas, pero se negó la posibilidad de que el Parlamento tratase los temas relacionados con la pandemia. Sólo al final de mes se previó una comparecencia del Ministro de Sanidad en la correspondiente comisión... que decayó por su dimisión para ser candidato a la Generalitat de Cataluña. El relato de los hechos es suficientemente elocuente como para no necesitar reflexión adicional alguna.

Como señalé, es muy pronto para valorar el hacer de los Parlamentos autonómicos en esta segunda etapa. En todo caso, transcurridos ya dos meses desde que se declaró la segunda alarma y, por ende, recayó sobre los mismos gran parte del protagonismo sobre el control de la gestión de la pandemia, es posible afirmar que las señales ratifican la inanidad diagnosticada en la primera etapa. Como pauta general, han seguido desempeñando sus funciones como lo hacían hasta ahora, es decir, sin prever procedimientos extraordinarios en relación con la pandemia ${ }^{31}$. Los Parlamentos nada pueden decidir en relación con la alarma por lo que su ejercicio se encuentra básicamente relacionado con

${ }^{31}$ La excepción la constituye la reforma del Reglamento de las Islas Baleares de 29 de diciembre de 2020, al objeto de regular, mediante la incorporación de un título específico, el trabajo del Parlamento cuando "Circunstancias de ámbito general de carácter grave y extraordinario impidan la participación presencial de diputados y diputadas". 
las funciones de control e impulso, amén del hacer legislativo que corresponda. Pero ello no obsta para que en el ejercicio de esas funciones se actúe con la singularidad que merece la ocasión. Una comisión de seguimiento específica; rendición de cuentas periódica del Presidente y de los Consejeros más afectados; o sesiones monográficas sobre la evolución de la pandemia, son sólo algunas de las maneras que habrían tenido estas instituciones para responder a la especial situación creada por la pandemia y, en concreto, a la delegación de funciones establecida en el decreto del segundo estado de alarma. Tampoco se ha desarrollado el principio de Parlamento abierto incorporado a numerosos reglamentos y que podía, por ejemplo, haber contribuido a suministrar a los ciudadanos una fuente relevante de Información y habilitar su participación en relación con sus inquietudes derivadas de la excepcional situación vivida. La pandemia no es un acontecimiento más. Su relevancia es extraordinaria y transversal y los Parlamentos deberían haber sido coherentes con esa excepcionalidad.

Por lo demás, no hubiese estado de más que hubiesen servido al principio de colaboración entre las Comunidades Autónomas, incentivando una imagen de unidad en la respuesta que los ciudadanos han echado en falta. Sin duda, los Parlamentos no son responsables de la imagen de confusión y de la incertidumbre provocada por gestión autónoma por cada Comunidad Autónoma de la situación. Pero podrían haber contribuido a paliarla, transmitiendo una imagen de unidad en la adopción de ciertas medidas.

Hay que insistir. No es sólo una cuestión de hacer concreto, de la adopción de determinadas medidas. Ni siquiera del ejercicio del control necesario. Es una cuestión de liderazgo político. La situación creada por la covid-19 ha sido, es, lo suficientemente grave como para que las instituciones eleven sus miras y den a la sociedad la respuesta en forma de referente que necesita. En este sentido, la pandemia era para el Parlamento, cabe anticiparlo, una oportunidad desaprovechada.

En todo caso, lo sucedido durante estos meses ha acabado por dar visibilidad a una característica del hecho parlamentario en España tan objetiva como desdeñada. Me refiero a su globalidad. El quehacer que corresponde al Parlamento en un País es en España el juicio que merezca el trabajo de sus dieciocho Parlamentos. Cada uno en su ámbito y en la medida de sus posibilidades contribuye a la representatividad de la sociedad, síntesis última de su razón de ser. Con la pandemia, ello se ha hecho plenamente visible. 
Enjuiciar la labor del Parlamento durante la misma exige acercarse a esa imagen global. $Y$ aunque el juicio no pueda ser positivo (se constata que los vicios son derivados de una misma cultura), sí lo es el hecho en sí de la existencia de esa imagen de globalidad.

Es tiempo de concluir. Mi juicio no es positivo. El Parlamento no ha ocupado el lugar que le correspondía en una situación extraordinaria. No ha ejercido como debiera ninguna de las funciones que le son propias. $\mathrm{Ni}$ ha controlado adecuadamente; ni ha ejercido la correspondiente función de impulso; ni siquiera ha usado sus facultades legislativas para, al menos, aportar seguridad jurídica; y tampoco ha sido referente para la sociedad. Una vez más, ha sido una institución marginal. $Y$ no cabe engañarse. Desde luego, el poder ejecutivo, y en particular el Gobierno de la Nación, no han tenido ningún interés en que las cosas transcurriesen de forma diferente. Pero, como se dijo, lo más grave es que desde los Parlamentos, no ha habido reacción. No se ha adoptado ninguna iniciativa coherente con la gravedad de la situación y que contribuyese a otorgar a la institución el lugar que le corresponde. Los gobiernos se han impuesto incluso con radicalidad y, una vez más, se ha demostrado que también gobiernan el Parlamento, sin que este pueda o sepa ejercer el mínimo de autonomía política que es exigible.

Una oportunidad perdida. Sí. Porque esta situación ofrecía a los distintos Parlamentos una ocasión única para singularizarse y demostrar su razón de ser. Para demostrar que, más allá de la retórica y de las premisas normativas, un Parlamento es imprescindible para el adecuado desenvolvimiento de la democracia. De una democracia moderna. Porque una crisis como esta permitía desarrollar una forma de proceder que conjugase los valores más clásicos del Parlamento con la recuperación de la idea de eficacia y el desarrollo de los nuevos valores del Parlamento abierto. Una excelente oportunidad para desmentir tópicos ha sido perdida. Al menos, se debería ser consciente de las consecuencias. Hay que saber que la erosión continúa. La democracia no se defiende desde la retórica de la coyuntura. Se defiende desde el compromiso incondicional con sus instituciones y con los valores que la sustentan. 